\title{
Performance Analysis of Different Propulsion Systems for LNG Carriers
}

\author{
Walid M Bahgat $^{+*}$ and Ahmed Salem ${ }^{\ddagger}$ \\ ${ }^{\dagger}$ Department of Marine Engineering, Faculty of Maritime Studies, King Abdulaziz University, Jeddah, Saudi Arabia \\ ${ }^{\ddagger}$ Engineering Upgrading Studies Institute, Arab Academy for Science, Technology \& Maritime Transport, Alexandria, Egypt \\ Received 01 Sept 2017, Accepted 05 Nov 2017, Available online 12 Nov 2017, Vol.5 (Nov/Dec 2017 issue)
}

\begin{abstract}
This paper analyses the performance of different propulsion systems which are used in LNG vessels. Additionally, it discusses the effect of replacing steam turbine with other prime movers at the same power. Furthermore, the paper includes the comparison between steam turbine, slow-speed diesel engine, gas turbine, combined diesel and steam cycle and combined gas and steam cycle with respect to its performance that comprise the thermal efficiency, SFC specific fuel consumption and the boil-off gas SFC for each one. In a nut shell, it could be noticed that the steam turbine and gas turbine propulsion systems are almost equal in thermal efficiency and a quiet difference in SFC. After words, there is a slight increase in thermal efficiency and specific fuel consumption by applying the combined cycle gas and steam. Moreover, by using diesel engine propulsion system the thermal efficiency went up to $52.26 \%$ and the SFC reached its lowest value, the thermal efficiency value of the combined cycle diesel and steam climbed to $58.36 \%$ with considerable decrease in SFC. Finally, by knowing the fuel consumption for each propulsion system, the most efficient propulsion system can be identified.
\end{abstract}

Keywords: propulsion systems; steam turbine, slow-speed diesel engine, gas turbine, thermal efficiency

\section{Introduction}

Over the last several decades, the clear majority of LNG carriers have been driven by steam turbine propulsion system. This type of propulsion was applied because of its ability to burn the boil off gas in the boiler and its reliability when compared to other alternatives. Furthermore, according to the apparent drawbacks for the steam propulsion system, it seems to be less attractive alternative due to its lower efficiency and high fuel consumption. Moreover, it needs a large space for engine room, propulsion redundancy is limited, its high initial cost for installation and the shortage of experienced engineers. Therefore, it was necessary to search which of propulsion system is the most efficient one in accordance with its performance to apply it in LNG carrier.

The research paper reviews the different propulsion systems as an alternative to steam turbine propulsion system like slow speed diesel with re-Liquefaction (DRL), dual fuel diesel electric (medium speed diesels) (DFDE), Gas Turbine, high pressure gas injection slow speed diesel (dual fuel diesel) (DFD), combined diesel and steam cycle (CODAS) and combined gas and steam cycle (COGAS).

There are some factors that should be considered when selecting the propulsion system which are the

*Corresponding author's ORCID ID: 0000-0001-5786-1651 DOI: http://Dx.Doi.Org/10.14741/ljmcr/5.6.13 changes in the LNG shipping, the performance analysis that includes thermal efficiency and the specific fuel consumption of each propulsion system and the comparison between different propulsion systems applied for LNG carriers. This paper viewed the different propulsion alternatives for LNG vessels that can be attractive in regard with high thermal efficiency and economically 'better' than the traditional steam turbine option [1].

The rapid expansion of the LNG shipping fleet includes 410 LNG carriers as of January 2016, with a total cargo carrying capacity of 60 million cubic meters but the problem which faces this expansion is the shortage of qualified personnel to operate steam turbine ships. Also, the combined cycle systems COGAS (Combined Gas and Steam) that have thermal efficiencies greater than diesel engine propulsion systems have the same difficulty. In this propulsion, the gas is burnt in a gas turbine and the waste heat from the gas turbine utilized to generate steam to operate a supplementary steam turbine [2]. Furthermore, other propulsion systems are also under discussion known as Gas Turbine Electric Propulsion which use Gas Turbines as a prime mover; however, the electric distribution and propulsion system will be same as Dual-Fuel electric propulsion system $[3,4]$.

The procedures have been carried out for case study "AL HAMRA" as LNG carrier with steam power plant rated for $29 \mathrm{MW}$. Moreover, the scenario can be summarized as 
studying the effect of changing the prime mover of steam LNG carrier "AL HAMRA" with other propulsion alternatives which are slow speed diesel engine, gas turbine, combined cycle diesel and steam (CODAS) and combined cycle gas and steam (COGAS). This paper will discuss in details the effect of replacing steam turbine with other prime movers which are mentioned above at the same power. Also, the research will include comparison between steam turbine, slow speed diesel engine, gas turbine, CODAS cycle and COGAS cycle with respect to its performance that includes the thermal efficiency, SFC and BOG SFC for each propulsion system.

\section{LNG Carriers}

In general, the cargo capacity of LNG ships varies from 1,000 cubic meters to 267,000 cubic meters. Also, the modern LNG vessel's capacities ranges from 125,000 m3 to $150,000 \mathrm{~m} 3$ but the capacity of small LNG carriers vary from 1,000-25,000 m3 that operate in some areas, such as Norway and Japan. Finally, most of LNG vessels have been constructed to transfer its cargo either in spherical design that is called "Moss Tank" or in geometric membrane design named as "Membrane Tank" [5].

\section{Considerations for Propulsion Selections}

First, the propulsion plant efficiency is one of the critical factors that determine the fuel consumption and the remaining cargo carrying capacity space. Second, the propulsion system should be able to utilize boil-off gas safely and easily in which the evaporated quantity of LNG that emit from cargo tanks ranges from 0.1 to $0.15 \%$ per day during the ship's loaded voyage $[6,7]$. This quantity of gas is evaporated in order to control the temperature and pressure in the cargo tanks. Hence, by using LNG as fuel in a given plant it will save up to $25 \%$ of fuel weight because the calorific value of natural gas is $13000 \mathrm{kcal} / \mathrm{kg}$ while the HFO calorific value is $10280 \mathrm{kcal} / \mathrm{kg}$. Therefore, it is better to use BOG as fuel by burning it in a steam boiler. Moreover, the recent technologies allow the BOG to be used as fuel in diesel engines. Additionally, the liquefaction plants are developed to return the BOG in the cargo tanks. Finally, the propulsion alternatives should be able to improve its operational efficiency and decrease the machinery space in order to increase the cargo carrying capacity $[8,9]$.

\section{Propulsion Systems Commonly Used in LNG Carriers}

This section will review the two types of marine steam propulsion system which are the conventional steam turbine and ultra-steam turbine.

\subsection{Conventional Steam Turbine}

In the last few years ago, steam turbines were used for almost all LNG vessels for the propulsion plant. The plant contains boiler which supplies steam to the cycle components (high pressure turbine, low pressure turbine and condenser). These turbines drive a single screw propeller via reduction gear. Also, the steam drives electric generators to provide power for many auxiliaries and supply the heat source to fuel tanks and air conditioning. The steam flows from boiler to high pressure steam turbine, low pressure turbine and finally to the condenser [10].

\subsection{Ultra-Steam Turbine Propulsion}

For several years, the steam turbine propulsion system has high reliability since it was installed in LNG vessels. Additionally, the steam propulsion efficiency is nearly reaches to $35 \%$ at full load which is the main disadvantage of the system. Furthermore, the turbo generator's efficiency is lower than the main steam propulsion turbine. In this propulsion system, there are two main boilers used for feeding superheated steam to high and low-pressure steam turbines that can burn both of heavy fuel oil and boil-off gas. Also, these two steam turbines are utilized to provide the electric power. Normally, there are two steam turbo generators are fitted to generate electric power with one or two diesel generators, which are only standby during maneuvering or in port.

The boil-off gas which is emitted from LNG cargo tanks is compressed in a single-stage centrifugal type LD (Low Duty) gas compressor to feed the boilers. The amount of gas supply is regulated by using a gas compressor equipped by inlet vane and variable speed electric motor. Therefore, the main disadvantage of a steam plant is its low thermal efficiency with high specific fuel consumption, high $\mathrm{CO}_{2}$ emission, low power density and high initial costs $[11,12]$.

The power plant concept of an LNG carrier is shown in Figure 1 which includes a diagram configuration of two gas-burning boilers power the steam turbine that drives the propeller through a reduction gearbox. This example has a diesel generator set, and two steam turbine-driven alternators (turbo-generators), which are also fed by the two boilers [13].

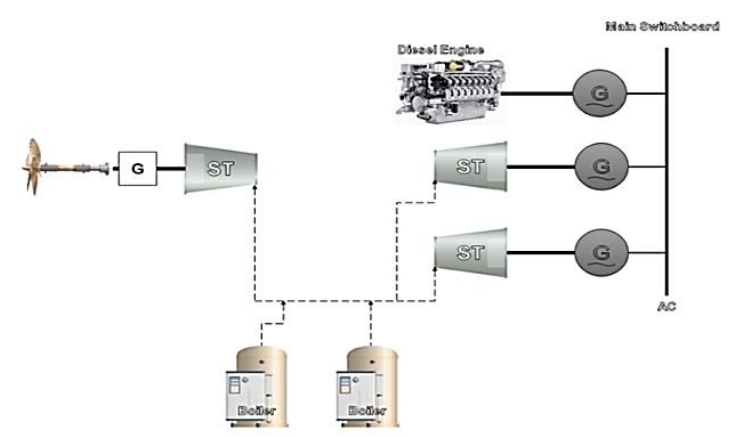

Fig.1: Steam power plant on board an LNG carrier, consisting of two boilers, a steam turbine, two turbo generators and a diesel generator set 


\subsection{Slow-Speed Diesel Engine with Gas Injection}

In this type of diesel engine, the gas fuel is injected directly to the combustion chamber with the aid of piston type gas compressor. The gas fuel is injected into the compressed scavenging air with pressurized gas fuel reaches 300 bar. Moreover, the gas diesel engine has high efficiency and the ability of burning a mixture of gas fuel and liquid fuel. Finally, by maintaining the mixing ratio between the gas fuel and heavy fuel oil, the gas injection diesel engine can burn both fuels at the same time.

\subsection{Medium-Speed Diesel Electric}

The medium-speed diesel engines are used in combination with electric propulsion. The diesel engines act as generator sets which transfer the power to the propeller through electric motors by using the reduction gear. Moreover, a dual fuel engines can be used for LNG carriers which can burn either gas with marine diesel oil as pilot fuel for injection, or diesel oil. However, when the $B O G$ is inadequate then the diesel engine can be operated by either D.O or HF.O. So, in this case a disposaloff BOG occurred by burning it in gas combustion unit (GCU). Finally, it can be changeover between either two modes of operation according to the required output power.

In the nut shell, the benefits of this type of diesel engines are its high efficiency, low emission, it increases the cargo carrying capacity when compared with steam propulsion and it has more flexibility to use different type of fuel. However, it has two disadvantages that it has high capital cost and it needs more maintenance $[5,12]$.

\section{Gas Turbine}

The advantages of gas turbine propulsion are its high thermal efficiency when compared with steam propulsion system, low emission level, low power/weight ratio, suitable machinery arrangement which increases the cargo carrying capacity, it has the lowest maintenance and capital cost of any major prime mover.

The fuel used in gas turbine propulsion can be forced boil-off gas or marine diesel oil which is like the mediumspeed diesel electric dual fuel gas and diesel oil propulsion system. Furthermore, the electricity is generated by the gas turbine driven alternators and is delivered to the high voltage bus bars. Also, the power for the propulsion motor is taken from bus bars and converted to supply a variable speed drive.

The gas turbine propulsion system has two alternatives:

1. Simple gas turbine cycle which includes one main gas turbine and one auxiliary turbine.

2. Combined gas, electric and steam cycle (COGES) which includes many gas turbines in addition to the heat recovery system in order to provide steam by using the exhaust gases which exit from the gas turbine to generate the electric supply. Moreover, this configuration gives $10 \%$ increase in overall efficiency when compared to the simple cycle.

\section{Combined Diesel and Steam Cycle (CODAS)}

By utilizing turbo-compounded diesel engine, heat recovery steam generator (HRSG) and steam turbine generator, the diesel engine efficiency can be enhanced. Figure 2 shows turbine Generator, and steam turbine which is operated by exhaust gases from diesel engine.

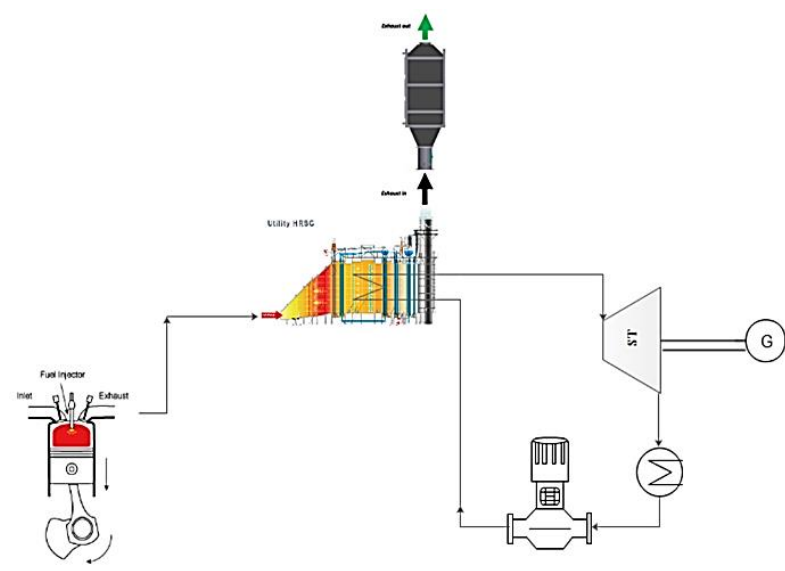

Fig. 2: Combined cycle: diesel engine, HSRG and steam turbine

\section{Combined Gas and Steam Cycle (COGAS)}

In the combined gas and steam cycle, exhaust gases emits from gas turbine to generate steam to operate the steam turbine. So, the power plant efficiency will be increased but the initial costs raised to its highest limit [13]. Figure 3 shows a schematic diagram of the combined gas and steam cycle (COGAS) which is considered to have high efficiency and high power. However, this approach has the following two disadvantages: first, low efficiency of the condensing exhaust steam cycle, second, substantial increase in capital cost due to the condensing turbine and condenser (or cooling towers).

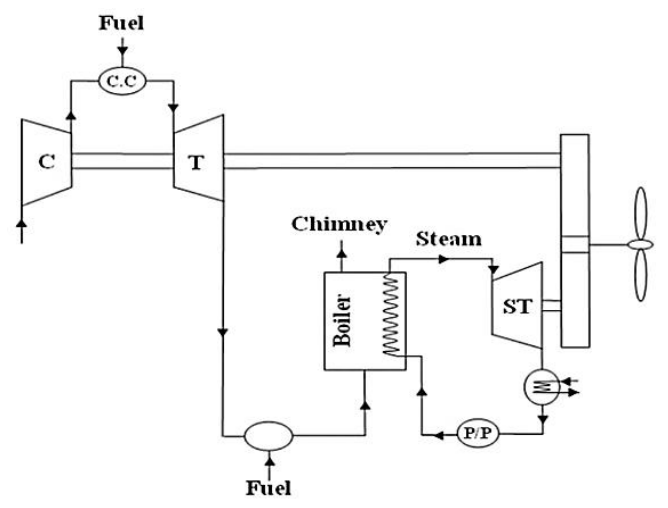

Fig. 3: Combined cycle gas and steam 


\section{8. "AL HAMRA" LNG Carrier as a Case Study}

The propulsion system of the case study "AL HAMRA" LNG carrier will be discussed in details in order to indicate its performance. So, according to its specifications it was built by Kvaerner Masa, Finland and delivered in January 1997 with a capacity of $136,357 \mathrm{~m}^{3}$ and it has a cargo tank of sphere shape (Moss type) constructed to transport the LNG with temperature $\left(-163^{\circ} \mathrm{C}\right)$ and at atmospheric pressure. This ship has IMO No. 9074640 with Liberian flag and its class is Lloyd's Register Classification (+100A1) [14].

The ship propulsion system is a steam propulsion system as in Figure 4. It consists of impulse steam turbine made by Mitsubishi (MS 40-2) unit developing power 40,217 SHP (29,600 kW). This is supplied with steam from two boilers UME-67/51 arranged to burned oil or boil of gas. An integral gearbox reduces turbine speed to $85 \mathrm{rpm}$ at FPP. Figure 5 shows a T-S diagram for the propulsion system of the ship [15].

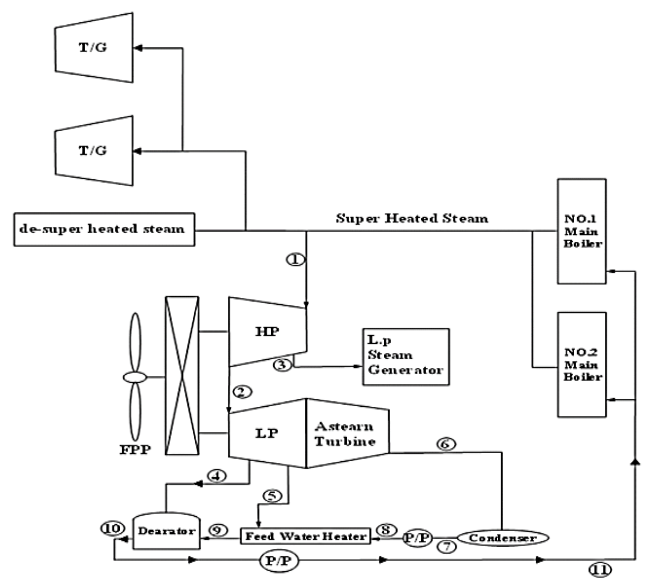

Fig. 4: Steam propulsion system components

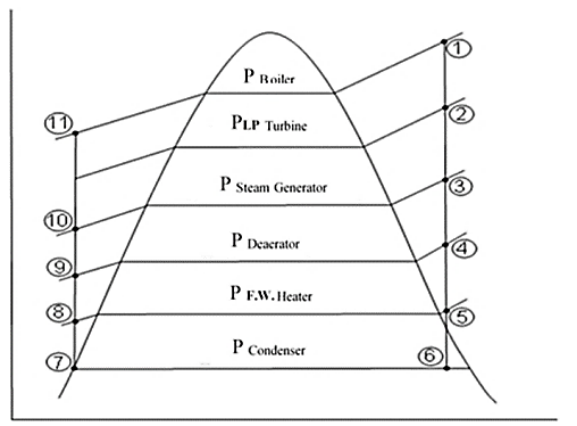

Fig. 5: T-S Diagram for steam propulsion system

The system provided to supply superheated steam with parameters of 62 bars and $515^{\circ} \mathrm{C}$. A high quality superheated steam is provided from two main boilers (Mitsubishi MB4E) to supply very important items in the engine room.

These items are:

1) Main turbines (two ahead turbines H.P and L.P) and one astern turbine.
2) Turbo generators (2-sets).

3) Turbo feed pumps (2-sets).

4) Dump valves (1 large and 1 small)

The two main steam lines as shown in Figure 4 come out from the two main boilers and connected together into one line goes to the maneuvering valve. Then, according to the position of the telegraph, the maneuvering valve will allow the steam to go to the high-pressure turbine then to the low-pressure turbine if it is for Ahead order or allow steam to go to the astern turbine if it is for astern order. The other two lines supply steam for turbo feed pumps for feeding the two main boilers with water and the other line for two turbo generators for generating the electricity for the ship. Also, there are two dump valves which are provided with motorized valve for allowing the excess steam of the system to dump valves which are opened usually during the maneuvering periods. Finally, the exhaust steam goes to the main condenser which converts steam into water and returns to the main boilers [15].

\section{Propulsion Alternatives}

In this section, the research will discuss the effect of replacing the propulsion system of the case study " $A L$ HAMRA" LNG carrier which is steam turbine with other prime movers with same power. Also, the research will include comparison between steam turbine, slow speed diesel engine, gas turbine, CODAS cycle and COGAS cycle with respect to the thermal efficiency, specific fuel consumption and BOG specific fuel consumption for each one. Moreover, this study regards to the key factors for selecting the prime mover to be applied for the propulsion system of the future LNG carriers.

\subsection{Replacing Steam Turbine with Slow-Speed Diesel Engine}

By using slow-speed diesel engine instead of steam turbine with the same power used on board LNG carrier "AL HAMRA". The design data of the slow-speed diesel engine which is used instead of the steam turbine can be described as shown in Table 1.

Table 1: Design data of slow speed diesel engine

\begin{tabular}{|c|c|}
$\begin{array}{c}\text { Hyundai-MAN B\&W, two-stroke, single acting, direct reversible, } \\
\text { cross-head type diesel engine with constant pressure } \\
\text { turbocharging }\end{array}$ \\
$\begin{array}{c}\text { Engine Model } \\
\text { No. of cylinders } \\
\text { Cylinder bore } \\
\text { Stroke }\end{array}$ & $6 S 90 \mathrm{MC}$ \\
\hline $\begin{array}{c}\text { Output power } \\
\text { Mean Effective Pressure }\end{array}$ & $900 \mathrm{~mm}$ \\
\hline Direction of rotation & $3188 \mathrm{~mm}$ \\
\hline Firing order & MCR 39900 BHP @ $76 \mathrm{RPM}$ \\
\hline $\begin{array}{c}\text { Starting Method } \\
\text { Fuel consumption }\end{array}$ & clockwise looking from aft \\
\hline
\end{tabular}


By using simple calculation and substituting in equations (1) and (2):

$$
\begin{aligned}
& \dot{m}_{f}=\frac{s f c * P_{b}}{0.75 * 3600} \\
& \eta_{b t h}=\frac{P_{b}}{\dot{m}_{f} * C . V}
\end{aligned}
$$

\section{where:}

$\dot{m}_{f}$ - The amount of fuel consumed by the engine per unit time $\mathrm{kg} / \mathrm{hr}$

$S f c$ - Specific fuel consumption

$P_{b}$ - Brake power $\mathrm{kg} / \mathrm{kW} \cdot \mathrm{hr}$

$\eta_{b t h}=$ brake thermal efficiency

c.v - The calorific value of the fuel $\mathrm{kJ} / \mathrm{kg}$

By using simple computer program, the first equation obtains the fuel mass flow rate $\left(\dot{m}_{f}\right)$ which is equal to $1.32 \mathrm{~kg} / \mathrm{s}$ and the second equation determines the brake thermal efficiency of diesel engine that reaches to 52.26 $\%$. So, this indicates that it is more than the thermal efficiency of steam turbine.

\subsection{Replacing Steam Turbine with Gas Turbine}

This study indicates the thermal efficiency and the specific fuel consumption of gas turbine by using EES program. So, by applying gas turbine instead of steam turbine as a prime mover by same power with the following design data of Gas Turbine which are summarized as shown in Table 2.

Table 2: Gas turbine design specifications

\begin{tabular}{|c|c|}
\hline Gas Turbine Model & LM2500PK \\
\hline Gas Turbine Output Power & $29000 \mathrm{~kW}$ \\
\hline Pressure Ratio & 22.8 \\
\hline Exhaust Gas Flow Rate & $87.7 \mathrm{~kg} / \mathrm{s}$ \\
\hline Exhaust Temperature & $519^{\circ} \mathrm{C}$ \\
\hline
\end{tabular}

The compression process of compressor turbine is isentropic according to the form of equation (3)

$\frac{T_{2^{\prime}}}{T_{1}}=\pi_{r}^{(\gamma-1) / \gamma}$

where:

$\pi_{r}=\left(\frac{P_{2}}{P_{1}}\right)=$ Compression Ratio in compressor.

The efficiency of the compressor $\eta_{c}$ can be expressed in the form of equation (4):

$\eta_{c}=\frac{T_{2^{\prime}}-T_{1}}{T_{2}-T_{1}}$

Assuming the air inlet temperature to the gas turbine as $27^{\circ} \mathrm{C}$ and from the design gas turbine data the pressure ratio is 22.8 . So that, by applying equation (3) it can be determine $T_{2}$. Then, by taking the compressor efficiency as $82 \%, T_{2}$ can be calculated from equation (4).
Moreover, by knowing the thermal efficiency of gas turbine which is $38 \%$ and the calorific value of the fuel then the mass flow rate of fuel can be calculated from equation (1). Finally, the cycle efficiency can be obtained by using EES program.

\subsection{Replacing Steam Turbine with Combined Diesel and Steam Cycle (CODAS)}

By replacing steam turbine with the combined cycle diesel and steam (CODAS) which has diesel engine power of $23450 \mathrm{~kW}$ and steam turbine power of $5693 \mathrm{~kW}$, therefore, it can obtain the total output power of 29143 $\mathrm{kW}$. In order to apply this combined cycle, it is necessary to select the suitable diesel engine power to be compatible with the steam turbine to reach the desired output power. So that, the efficiency of the combined cycle will be $58.36 \%$. The design data of the slow speed diesel engine which will be used in the combined cycle are shown in Table 3.

Table 3: Design data of slow-speed diesel engine

\begin{tabular}{|c|c|}
\hline Engine type & $\begin{array}{c}\text { Hyundai-MAN B\&W 2-Stroke, } \\
\text { single acting, direct reversible } \\
\text { crosshead type diesel engine with } \\
\text { constant pressure turbocharging }\end{array}$ \\
\hline Model & S80MC \\
\hline Number of cylinder & 7 \\
\hline Cylinder bore & $800 \mathrm{~mm}$ \\
\hline Stroke & $3056 \mathrm{~mm}$ \\
\hline Output power & $23450 \mathrm{~kW}(31920 \mathrm{HP})$ \\
\hline Revolution & $77 \mathrm{RPM}$ \\
\hline Mean effective & $17 \mathrm{~kg} / \mathrm{cm}^{2}$ \\
\hline pressure & $130 \mathrm{~kg} / \mathrm{cm}^{2}$ \\
\hline Maximum pressure & $7.84 \mathrm{~m} / \mathrm{s}$ \\
\hline Mean piston speed & Clock wise looking from aft \\
\hline Direction of rotation & Compressed air $30 \mathrm{~kg} / \mathrm{cm}^{2}$ \\
\hline Starting air & $1-7-2-5-4-3-6$ \\
\hline Firing order & \\
\hline &
\end{tabular}

By using EES program the heat added to the steam cycle can be obtained. Then, by knowing the enthalpy of both the superheated steam and the boiler inlet steam, the steam mass flow rate can be determined. After words, by assuming the condenser pressure, so the enthalpy of condenser inlet and exit can be obtained. Moreover, the pump power can be determined. Also, by substituting the pump power, the steam power can be determined and the steam efficiency can be obtained. Finally, the combined power of diesel engine and steam turbine can be obtained and the total efficiency of the combined cycle can be determined from Equation 5 .

$\eta_{\text {combined }}=\frac{P_{s t}+P_{b}}{m_{f} \times c v}$

where:

$P_{\text {combined }}=P_{\text {net }}+P_{b}$

$P_{n e t}$-The net power of the steam cycle $\mathrm{kW}$

$P_{b}$ - Diesel engine power $\quad \mathrm{kW}$ 


\subsection{Replacing Steam Turbine with Combined Gas and Steam cycle (COGAS)}

The combined cycle (COGAS) can be applied instead of the steam turbine which already used in the case study LNG carrier. This combined cycle contains gas turbine which has a power of $26463 \mathrm{~kW}$ and steam turbine power of $2824 \mathrm{~kW}$ to obtain the desired output power of 29287 $\mathrm{kW}$. Additionally, to apply this combined cycle, it is necessary to determine the suitable gas turbine to be compatible with the steam turbine. Consequently, the efficiency of the combined cycle will be $45.28 \%$ which is better than the steam turbine and gas turbine efficiencies. After words, the design data of Gas Turbine are summarized as shown in Table 4.

Table 4: Gas turbine design data

\begin{tabular}{|c|c|}
\hline Gas Turbine Model & LM2500PH \\
\hline Gas Turbine Output Power & $26463 \mathrm{Kw}$ \\
\hline Pressure Ratio & 19.4 \\
\hline Exhaust Gas Flow Rate & $76.2 \mathrm{~kg} / \mathrm{s}$ \\
\hline Exhaust Temperature & 500 \\
\hline
\end{tabular}

\section{Comparison between different propulsion system options}

First of all, the scenario of this paper is to study the LNG carrier "ALHAMRA" which use steam turbine as a propulsion system and compare it with other propulsion systems. The comparison is carried out in order to know which one is the best propulsion according to its performance that includes the thermal efficiency, specific fuel consumption and the specific fuel consumption by using boil-off gas for each propulsion system. Secondly, Table (5) shows characteristic values for each propulsion system.

Table 5: Comparison between propulsion systems, its thermal efficiencies specific fuel consumptions when using either fuel or boil-off gas

\begin{tabular}{|c|c|c|c|}
\hline $\begin{array}{c}\text { Propulsion } \\
\text { System }\end{array}$ & $\begin{array}{c}\text { Thermal } \\
\text { Efficiency }\end{array}$ & S.F.C & (S.F.C $)_{\text {bog }}$ \\
\hline Diesel engine & 0.5226 & 0.164 & 0.137 \\
\hline Gas turbine & 0.38 & 0.21 & 0.189 \\
\hline Steam turbine & 0.386 & 0.241 & 0.206 \\
\hline CODAS & 0.5836 & 0.174 & 0.153 \\
\hline COGAS & 0.4528 & 0.182 & 0.159 \\
\hline
\end{tabular}

Figure 6 shows the comparison between the thermal efficiencies of alternative propulsion systems. Therefore, it can be noticed that the combined cycle CODAS rose to the peak value of thermal efficiency and gas turbine propulsion system dropped to the lowest value. Then, by comparing steam turbine thermal efficiency with the other propulsion systems, it can be clearly seen that by applying the combined cycle COGAS the thermal efficiency went up to $45.28 \%$ which is better than steam turbine and gas turbine propulsion systems efficiencies. After that, the diesel engine propulsion system thermal efficiency climbed to $52.26 \%$ which is higher than steam turbine, gas turbine and the combined cycle COGAS thermal efficiencies. Finally, the combined cycle (CODAS) has the best thermal efficiency because it is reached to $58.36 \%$ which is the highest value.

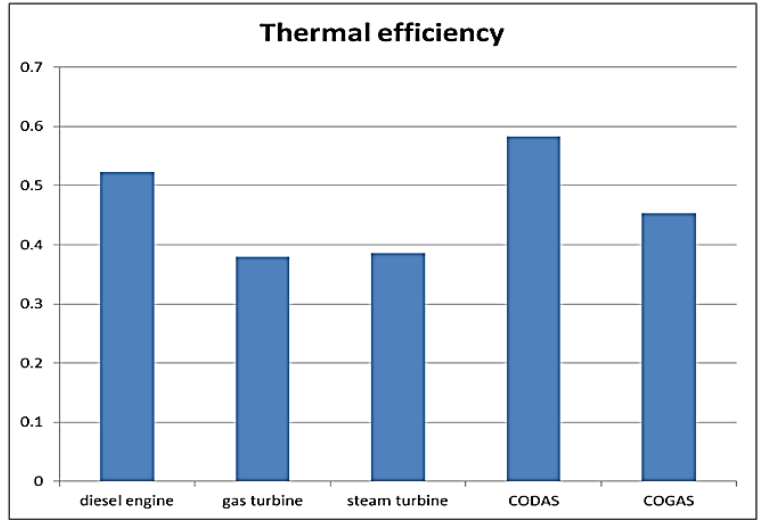

Fig. 6: Comparison between different propulsion systems and their thermal efficiencies

Figure 7 indicates the comparison between different propulsion systems and their specific fuel consumption (S.F.C). So, it can be noticed that the steam turbine propulsion system has the highest S.F.C and diesel engine propulsion system has the lowest S.F.C. Then, by comparing steam turbine propulsion system S.F.C with the other propulsion systems, it can be clearly seen that by applying diesel engine propulsion system the S.F.C fell down to $0.164 \mathrm{~kg} / \mathrm{kW} . \mathrm{hr}$ which is smaller than the S.F.C of other propulsion systems. After that, there has been a slight increase in S.F.C of the combined cycle (CODAS) to be $0.174 \mathrm{~kg} / \mathrm{kW} . \mathrm{hr}$ and the combined cycle (COGAS) to be $0.182 \mathrm{~kg} / \mathrm{kW} . \mathrm{hr}$. Then, the gas turbine propulsion system S.F.C rose to $0.21 \mathrm{~kg} / \mathrm{kW} . \mathrm{hr}$ and the steam turbine propulsion system S.F.C climbed to $0.241 \mathrm{~kg} / \mathrm{kW} . \mathrm{hr}$ which are the highest S.F.C value.

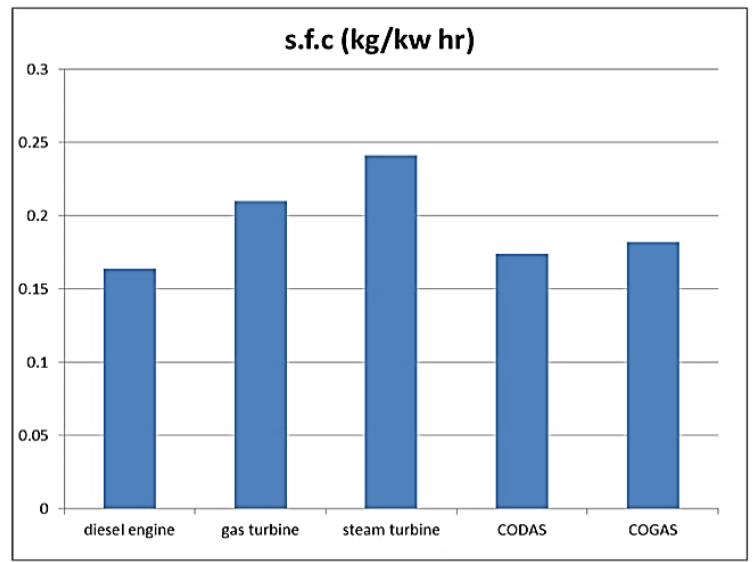

Fig. 7: Comparison between different propulsion systems $\&$ their specific fuel consumption 
Figure 8 depicts the comparison between different propulsion systems and their specific fuel consumption by using boil-off gas. Therefore, it can be seen that the steam turbine propulsion system has the maximum BOG specific fuel consumption which is $0.2 \mathrm{~kg} / \mathrm{kW} . \mathrm{hr}$ and diesel engine propulsion system has the minimum BOG S.F.C. Then, by comparing steam turbine propulsion system BOG S.F.C with the other propulsion systems, it can be clearly seen that by applying diesel engine propulsion system the BOG S.F.C fell down to 0.137 $\mathrm{kg} / \mathrm{kW} . \mathrm{hr}$ which is smaller than the other S.F.C of these different propulsion systems. After that, there has been a slight increase in BOG S.F.C of the combined cycle (CODAS) and the combined cycle (COGAS) which are almost equal to $0.15 \mathrm{~kg} / \mathrm{kW} . \mathrm{hr}$. Then, the gas turbine propulsion system BOG S.F.C rose to $0.189 \mathrm{~kg} / \mathrm{kW} . \mathrm{hr}$ which is the highest value.

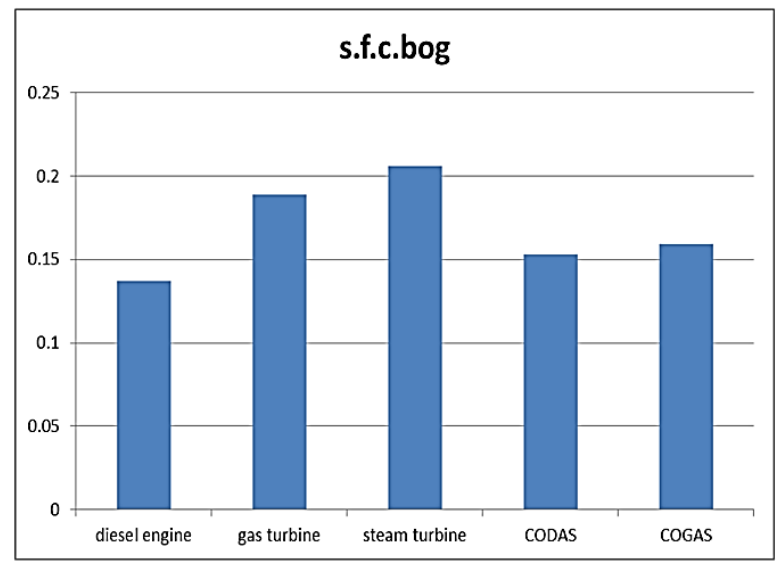

Fig. 8: Comparison between different propulsion systems and their specific fuel consumption by using boil-off gas as fuel

In a nut shell, it can be noticed that the efficient propulsion system is the combined cycle diesel and steam (CODAS) which has high thermal efficiency of $58.36 \%$ and the specific fuel consumption is reduced by $27.8 \%$ when compared with steam turbine propulsion system.

\section{Conclusion}

This paper seeks for the most efficient propulsion system by analyzing the performance of various propulsion options to be used in LNG carriers. Therefore, it was essential to review the several types of propulsion systems in order to differentiate between them. So, the performance analysis includes calculation of their thermal efficiencies and its specific fuel consumption for each propulsion alternatives.

The effect study changing the prime mover of steam LNG carrier with other propulsion alternatives which are slow speed diesel engine, gas turbine, combined cycle diesel and steam (CODAS) and combined cycle gas and steam (COGAS). The paper discussed the effect of replacing steam turbine with other prime movers which are mentioned above with the same power. Also, it includes the comparison between steam turbine, slow speed diesel engine, gas turbine, CODAS cycle and COGAS cycle with respect to the thermal efficiency, S.F.C and the boil-off gas S.F.C for each one. Moreover, this study regards to the key factors for selecting the prime mover according to the thermal efficiency and S.F.C to be applied for the propulsion system of the future LNG carriers. Furthermore, it is noticed that the steam turbine and gas turbine propulsion systems are almost equal in thermal efficiency and there is a slight increase in thermal efficiency by applying the combined cycle COGAS Additionally, by using diesel engine propulsion system the thermal efficiency went up to $52.26 \%$ and the thermal efficiency value of the combined cycle CODAS climbed to $58.36 \%$ which is the highest point. Actually, by knowing the S.F.C for each propulsion system, the most efficient propulsion system can be selected instead of the steam turbine propulsion system. In addition, the steam turbine has the highest specific fuel consumption which can be considered as a demerit for this propulsion system and diesel engine propulsion system has the lowest S.F.C which could be considered as a merit. However, there is a slight increase in S.F.C for both combined cycles CODAS and COGAS. Moreover, the gas turbine propulsion system S.F.C increased sharply which is disadvantage of this propulsion system. So, it is better to use diesel engine, combined cycle (CODAS) and combined cycle (COGAS) propulsion systems which have low S.F.C. Furthermore, by using boil-off gas the steam turbine has the highest S.F.C compared with diesel engine propulsion system. There is a slight increase in boil-off gas (BOG) S.F.C for both combined cycles CODAS and COGAS. Finally, the gas turbine propulsion system S.F.C increased moderately which is the disadvantage of this propulsion system. So, it is better to use diesel engine, combined cycle (CODAS) and combined cycle (COGAS) propulsion systems which have low specific fuel consumption.

\section{References}

[1]. Wayne W.S.: The options and evaluation of propulsion systems for the next generation of LNG carriers. In $23^{\text {rd }}$ World gas conference, Amsterdam 2006.

[2]. Nandkishore G.: LNG ships and their future. American Eagle Tanker Inc. Technical Report, 2007.

[3]. Hansen, J.F. and Lysebo, R.: HV Electric Power and Propulsion Solutions for New Generation of LNG Carriers with Various Propulsion Systems. In Proc. of the 28th Annual Event "The MotorShip Propulsion Conference", Copenhagen 2006.

[4]. Courtay R., Claes L., Sainson J.: LNG Carriers Using Gas Fuel Only Diesel Gas Electric Propulsion [C]. InProc. of the $14^{\text {th }}$ International Conference \& Exhibition on Liquefied Natural Gas, Doha 2004 Mar, pp. 75-79.

[5]. The international group of liquefied natural gas importers, "LNG ships", 2011. http://www.giignl.org (accessed February 2011). 
[6]. Namba N., Shuku M., Yuasa K., Ishimaru J.: Transportation of clean energy at sea. Mitsubishi LNG carrier, at present and in future. Mitsubishi Heavy Industries Technical Review, 2003; 40(1): pp. 1-6.

[7]. El-Gohary M.M.: The future of natural gas as a fuel in marine gas turbine for LNG carriers. Proceedings of the Institution of Mechanical Engineers, Part $M$ : Journal of Engineering for the Maritime Environment, UK 2012; 226(4): pp. 371-377.

[8]. Javanmardi J., Nasrifar K., Najibi S.H., Moshfeghian M.: Feasibility of transporting LNG from South-Pars gas field to potential markets. Applied thermal engineering, 2006; 26(16): pp. 1812-1819.

[9]. Yuasa K., Uwatoko K., Ishimaru J.: Key Technologies of Mitsubishi LNG Carriers-Present and Future. Mitsubishi Heavy Industries Technical Review, 2001; 38(2): pp. 47-51.

[10]. Gilmore R., Hatzigrigoris S., Mavrakis S., Spertos A., Vordonis A.: LNG carrier alternative propulsion systems. SNAME-Greek section, 2005
[11]. Sinha R.P., Nik W.M.: Investigation of propulsion system for large LNG ships. In IOP Conference Series: Materials Science and Engineering 2012 (Vol. 36, No. 1, p. 012004). IOP Publishing.

[12]. Ganesen A.: Alternative Propulsion System for LNG Ship. International Gas Union Research Conference, (IGRC-2008) Paris 8 October 2008

[13].Stapersma D., Woud H.K.: Institute of Marine Engineering, Science and Technology (United Kingdom); Design of propulsion and electric power generation systems. London (United Kingdom): IMarEST; 2002.

[14]. National Gas Shipping Company, Abu Dhabi National Tanker Co., "AL HAMRA General Arrangement", 1997. http://www.ngsco.com/en/ngsco/specs/AlHamra.pdf (accessed September 2010)

[15]. Kawasaki URA turbine catalogue, 2001. http://www.khi.co.jp/english/machinery/product/ship/ship .html (accessed May 2011). 